\title{
Evaluation of the Lipid Quality of Lyophilized Pasteurized Human Milk for Six Months by GC-FID and ESI-MS
}

\author{
Luciana P. Manin, ${ }^{\oplus a}$ Adriela A. Rydlewski, ${ }^{\circledR a}$ Marília B. Galuch, ${ }^{\circledR b}$ Jessica S. Pizzo, ${ }^{\circledR b}$ \\ Caroline D. Zappielo, ${ }^{\oplus b}$ Carlos E. R. Senes, ${ }^{b}$ Oscar O. Santos ${ }^{\oplus a, b}$ and Jesuí V. Visentainer ${ }^{*, a, b}$ \\ aPrograma de Pós-Graduação em Ciência de Alimentos, Universidade Estadual de Maringá (UEM), \\ 87020-900 Maringá-PR, Brazil \\ ${ }^{b}$ Departamento de Química, Universidade Estadual de Maringá (UEM), 87020-900 Maringá-PR, Brazil
}

\begin{abstract}
Human milk (HM) lipids provide about 50\% energy and facilitate the transport and absorption of fat-soluble vitamins for infants, but their composition should be studied when the milk is processed. This study evaluated the lipid quality of lyophilized and vacuum-packed colostrum (C), transitional (T), and mature (M) HM for a period of 1, 30, 60, 90, 120, 150, and 180 days of storage at $-18{ }^{\circ} \mathrm{C}$. From the acidity ( ${ }^{\circ}$ Dornic), lipid content, and fatty acid (FA) composition results, no significant differences in the analyzed period were observed. The relative percentage of major triacylglycerols (TAG) of the HM was not altered, showing that the lyophilization process in $\mathrm{HM}$ is a good alternative that could be applied in human milk banks (HMB), increasing HM preservation and facilitating its transport and storage.
\end{abstract}

Keywords: fatty acid composition, direct infusion mass spectrometry, human milk banks, storage conditions

\section{Introduction}

The American Academy of Pediatrics advises that human milk (HM) should be the exclusive source of nutrition until the first six months of life, ${ }^{1}$ providing nutrients, lipids, and bioactive components that aid in infant maturation and development, as well as protection against gastrointestinal diseases, protective effects against the development of diseases and infections, ${ }^{2-4}$ and resulting in the adaptation to the external environment of the mother's uterus. ${ }^{5} \mathrm{HM}$ has characteristics of a dynamic fluid and its composition varies according to the lactation cycle to meet the nutritional needs of growing babies. ${ }^{6} \mathrm{HM}$ is classified according to the lactation period of the mother as colostrum (C) (from the first to the seventh day), transitional (T) (from the eighth to the fourteenth day), and mature (M) milk (from the fifteenth day onwards). ${ }^{7}$

Water is the major component of HM, which accounts for approximately $90 \%$ of its composition. Lactose is present between 6.7 and $7.8 \%$, fat represents between 3.2 and $3.6 \%$, and protein represents between 0.9 and $1.2 \%$ of its composition. Fat is the most variable compound, mainly

*e-mail: jesuiv@gmail.com influenced by the lactation period (C, M and T), the feeding time (diurnal and nocturnal), the maternal diet (feeding), and the beginning and end of each baby's feed. However, the milk fat is subject to oxidative degradation. ${ }^{8-11}$

HM lipids provide half of the total energy of HM and facilitate the transport and absorption of fat-soluble vitamins for the baby. ${ }^{12,13}$ Fatty acids (FA) are their main constituents, found in the form of triacylglycerols (TAGs), and approximately 41,31 , and $25 \%$ are saturated (SFA), monounsaturated (MUFA), and polyunsaturated fatty acids (PUFA), respectively. Among them, palmitic acid (16:0) and oleic acid (18:1n-9) have higher proportions. ${ }^{12,14}$

When difficulties occur in the mother's breastfeeding process, the American Academy of Pediatrics ${ }^{1}$ recommends using pasteurized human donor milk. For this purpose, human milk banks (HMB) are responsible for the collection, sorting, processing, and distribution of HM to prescribed individuals. ${ }^{15}$ The processing imposed for HMB is pasteurization, which aims to reduce the risk of microbial contamination that may occur during collection and treatment. ${ }^{16,17}$ After the pasteurization process, the liquid $\mathrm{HM}$ is stored in a freezer.

However, the storage of the frozen HM in its liquid form can lead to the formation of ice crystals, which can damage 
some milk components ${ }^{18}$ and can break the emulsion between milk fat globules. The lipid fraction can also adhere to the container and is not recovered. ${ }^{19}$ Sousa and Silva ${ }^{20}$ observed a $23.3 \%$ reduction in lipid content of liquid HM that was frozen. This was due to fat globule membrane breakdown, the action of lipases, and the formation of a fat layer on the container wall. There may also be an increase in the concentration of unsaturated FAs with freezing time when analyzing pasteurized liquid HM which was frozen for 240 days. $^{21}$

The lyophilization technique is free of preservatives or chemicals and is used to prolong the shelf-life of the product, ceasing microbial growth and retarding the lipid oxidation process. ${ }^{22}$ In this process, HM is frozen at temperatures lower than $-20{ }^{\circ} \mathrm{C}$ under high vacuum (low pressure), causing the ice to sublime. The final product has low weight and easy storage. It is free of moisture and capable of being reconstituted with the addition of water. ${ }^{23}$ The use of the lyophilization process by the HMB can be a good alternative to extend HM useful life and to facilitate its transport and storage. ${ }^{24}$

The aim of this study was to analyze the lipid profile of three phases of pasteurized and lyophilized HM (C, T and $\mathrm{M}$ ) in order to evaluate the process of pasteurization plus lyophilization as a form of HM storage. The FA composition and the TAG profile of the pasteurized, lyophilized and vacuum-packed colostrum, transitional, and mature HM were obtained after 1, 30, 60, 90, 120, 150, and 180 days of storage $\left(-18^{\circ} \mathrm{C}\right)$ to assess if the HM lipids undergo changes over the storage period.

\section{Experimental}

\section{Samples}

The present study was approved by the Research Ethics Committee (CEP), number 2.797.476, from the State University of Maringá (UEM, Maringá, Paraná, Brazil). Samples of pasteurized C, T, and M HM were collected in an HMB from fifteen mothers for each HM phase at the University Hospital of Maringá (Maringá, Paraná, Brazil) with a cooling temperature of $4{ }^{\circ} \mathrm{C}$. Subsequently, the HM samples were separated into three pools according to their respective phases (with $500 \mathrm{~mL}$ each) and homogenized with a mixer (Viva Collection 400W RI136406, Philips Walita Ltd., São Paulo, Brazil) for $15 \mathrm{s.}{ }^{25}$ An aliquot (30 mL) of each HM phase was collected for subsequent analysis (samples $\mathrm{C} 0$, T0, and M0). Then, the remaining samples $(470 \mathrm{~mL}$ each) were weighed, lyophilized, vacuum-packed, and stored in a freezer at $-18{ }^{\circ} \mathrm{C}$ for 180 days in the absence of light. Samples of the lyophilized colostrum (CL), transitional (TL), and mature (ML) HM were analyzed at 0, 30, 60, 90, 120, 150 , and 180 days of storage.

Before the analysis, lyophilized samples were reconstituted by adding enough water to achieve the initial mass before the lyophilization process, for which the mass was checked before and after the process with an analytical balance.

\section{Reagents and standards}

Methanol, chloroform, $n$-heptane, and sodium chloride (all of analytical grade) were purchased from Synth (São Paulo, Brazil). Sodium hydroxide, ammonium chloride, and sulfuric acid (all of analytical grade) were purchased from Dinâmica (São Paulo, Brazil). Methanol and chloroform (both high-performance liquid chromatography (HPLC) grade) were purchased from J.T.Baker ${ }^{\circledR}$ (Philipsburg, United States) and Riedel-de Haën (Seelze, Lower Saxony, Germany), respectively. Ammonium formate (97\%) was purchased from Sigma-Aldrich (Darmstadt, Germany). For the performance of the gas chromatographic analyses, the reagents and solvents used were analytical grade, and for the mass spectrometry (MS) analyses the solvents were of HPLC grade.

\section{Lyophilization process}

Approximately $470 \mathrm{~mL}$ of each HM pool (C, T, and M) were frozen at $-18{ }^{\circ} \mathrm{C}$ and subsequently lyophilized in a lyophilizer (Alpha 1-2 LD Plus, model 101522, Osterode, Germany) at about $-54{ }^{\circ} \mathrm{C}$ and 0.021 mbar. The lyophilization process was continued until the achievement of constant weight, for approximately $48 \mathrm{~h}$, in triplicate. ${ }^{26}$

\section{Determination of acidity ( ${ }^{\circ}$ Dornic)}

The Dornic acidity of the HM samples was obtained according to Almeida et al. ${ }^{27}$ and Brazilian Health Regulatory Agency (ANVISA). ${ }^{28}$ The titrant solution was N/9 sodium hydroxide (Dornic solution) in the presence of phenolphthalein indicator. The analysis was performed in triplicate, considering that each $0.01 \mathrm{~mL}$ spent of Dornic solution to neutralize $1.0 \mathrm{~mL}$ of $\mathrm{HM}$ is equivalent to $1^{\circ}$ Dornic.

\section{Determination of total lipids}

The total lipids of HM pool samples were extracted according to Folch et al. ${ }^{29}$ Before performing the extraction, the lyophilized milk samples were reconstituted with water to simulate the actual composition consumed by the baby. 
Fatty acid composition by gas chromatography with flame ionization detector (GC-FID)

Fatty acid methyl esters (FAMEs) were prepared by methylation of total lipids according to Hartman and Lago, ${ }^{30}$ and modified by Maia and Rodriguez-Amaya. ${ }^{31}$

FAME analyses were carried out in a Thermo Scientific (Trace Ultra 3300, Waltham, United States) gas chromatography (GC) with a flame ionization detector (FID), a CP-7420 capillary column (100.0 m size, $0.25 \mathrm{~mm}$ internal diameter and $0.25 \mu \mathrm{m}$ cyanopropyl thin film as stationary phase), and a split/splitless injector. The detector and injector temperatures were at 250 and $230^{\circ} \mathrm{C}$, respectively. The GC-FID oven was programmed to $65^{\circ} \mathrm{C}$ and held for $4 \mathrm{~min}$, then heated to $185^{\circ} \mathrm{C}$ at $15^{\circ} \mathrm{C} \mathrm{min}^{-1}$ and held for $12 \mathrm{~min}$, then heated to $235^{\circ} \mathrm{C}$ at $20^{\circ} \mathrm{C} \mathrm{min}^{-1}$ and held for $14 \mathrm{~min}$. The gas flow rates used were $1.4 \mathrm{~mL} \mathrm{~min}^{-1}$

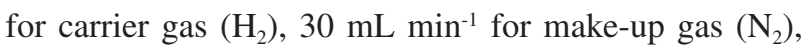
and 30 and $300 \mathrm{~mL} \mathrm{~min}{ }^{-1}$ for the flame gases $\left(\mathrm{H}_{2}\right.$ and synthetic air, respectively). Split injection mode was used with a 1:100 ratio, and the volume of sample injections was $2.0 \mu \mathrm{L} .{ }^{32}$ FAMEs were identified by comparison of the retention times of the sample constituents with those of analytical standards (FAME standard mixture, C4-C24, Saint Louis, United States, Sigma-Aldrich). The peak areas were determined using ChromQuest ${ }^{\mathrm{TM}} 5.0$ software, and the FA compositions were expressed as a relative percent of total FA. All samples were analyzed in triplicate.

Triacylglycerol (TAG) profile by direct infusion electrospray ionization mass spectrometry (ESI-MS)

HM lipid samples were prepared based on Galuch et al..$^{33}$ Approximately $50.0 \mu \mathrm{L}$ of the total lipid ("Determination of total lipids" sub-section) were added to $950.0 \mu \mathrm{L}$ of chloroform. Then, $5.0 \mu \mathrm{L}$ of this solution was added to a $1.0 \mathrm{~mL}$ methanol/chloroform solution with a 9:1 $\left(\mathrm{v} \mathrm{v}^{-1}\right)$ ratio. To obtain the ammonium adducts, $\left[\mathrm{TAG}+\mathrm{NH}_{4}\right]^{+}$, $20.0 \mu \mathrm{L}$ of $0.10 \mathrm{~mol} \mathrm{~L}^{-1}$ ammonium formate prepared in methanol was added to the final solution.

The prepared solutions were infused at a flow rate of $10.0 \mu \mathrm{L} \mathrm{min}^{-1}$ directly into a Xevo TQ-D ${ }^{\mathrm{TM}}$ triple quadrupole mass spectrometer (Waters, Milford, Massachusetts, United States) equipped with a $\mathrm{Z}$ spray ${ }^{\mathrm{TM}}$ electrospray ionization source operating in positive mode (ESI+) with the following MS conditions: desolvation gas flow $\left(500 \mathrm{~L} \mathrm{~h}^{-1}\right)$, source temperature $\left(150{ }^{\circ} \mathrm{C}\right)$, desolvation temperature $\left(200{ }^{\circ} \mathrm{C}\right)$, capillary and cone voltage ( $3.00 \mathrm{kV}$ and $20.00 \mathrm{~V}$, respectively) based on Silveira et al. ${ }^{34}$ The TAG profile of the HM lipid samples was evaluated in the mass range of $m / z 600-1000$. The results obtained were determined using MassLynx ${ }^{\mathrm{TM}}$ software.

\section{Statistics analysis}

The analysis of acidity in ${ }^{\circ}$ Dornic, the percentage of total lipids, and the composition of FA by GC-FID were submitted to statistical analysis of variance (ANOVA), and the means were compared by Tukey's test with a significance level of $95 \%$ using PAST software. ${ }^{35}$

\section{Results and Discussion}

\section{Determination of acidity ( ${ }^{\circ}$ Dornic)}

Acidity can be an indirect measure of the HM degree of contamination because lactose fermentation by bacterial growth increases the lactic acid and, consequently, increases HM acidity. ${ }^{36}$ In addition, acidity analysis is of great importance in evaluating the HM nutritional quality because the acidic or alkaline increase can cause necrotizing enterocolitis in infants with low weight. ${ }^{37}$

The acidity in Dornic should be in the range of 1.0-8.0 ${ }^{\circ}$ Dornic so that the HM can be considered appropriate for the consumption of the baby. It is also a quality parameter related to correct storage and is used in HM selection by HMB. ${ }^{28}$ This analysis was carried out monthly to monitor whether the acidity of HM changed with the lyophilization and storage process for six months (0-180 days), and Table S1 (in the Supplementary Information (SI) section) shows the results obtained during these months. The freezer storage of the C, T, and M HM in lyophilized forms did not significantly alter the acidity for six months since the acidity in Dornic values did not present significant difference at a confidence level of $95 \%$. In addition, $5.33{ }^{\circ}$ Dornic was the maximum value found, which is in the allowed range (1.0-8.0 ${ }^{\circ}$ Dornic) ${ }^{28}$

Fat content in colostrum (C), transitional (T), and mature (M) human milk (HM)

Lipids are considered the main source of energy, being responsible for $40-50 \%$ of the total caloric value of HM. ${ }^{38}$ Table S2 (SI section) shows the results of the lipid percentage of the $\mathrm{C}, \mathrm{T}$, and M HM before and after the lyophilization process and during six months of freeze storage of the lyophilized HM. The lipid percentages found ranged between 3.16 and $3.75 \%$ in the three types of milk.

The results (Table S2, SI section) did not have significant differences at a confidence level of $95 \%$, indicating that the lyophilization process did not modify the HM lipid percentage. The lipid percentage of the lyophilized C, T, and M HM remained constant when they were vacuum-packed 
and stored for six months in a freezer at $-18{ }^{\circ} \mathrm{C}$, showing that the lyophilization process was efficient.

\section{Fatty acid composition by GC-FID}

Twenty-five FAs were identified and quantified by GC-FID in the C (Table S3, SI section), T (Table S4, SI section), and M (Table S5, SI section) HM pool samples. In the Supplementary Information, Figures S1 to S9 show some examples of the chromatograms obtained.

The results showed that the lyophilization process did not change the FA composition of the $\mathrm{C}, \mathrm{T}$, and $\mathrm{M}$ HM since the results for the initial HM pool samples (C0, T0, and M0) did not differ significantly from the results obtained for lyophilized samples (CLO, TL0, and ML0, respectively).

The FA composition of the lyophilized C, T, and M HM did not change significantly (at a confidence level of 95\%) when the samples were vacuum-packed and stored in a freezer $\left(-18^{\circ} \mathrm{C}\right)$ for six months. There was only a significant change in the sum of MUFA for the T HM since the MUFA value was lower for 180 days of storage (TL180).

Lozano et al. ${ }^{39}$ studied the stability of FA during the storage of lyophilized HM, observing that for up to 90 days the lyophilization process was a good alternative to preserve breast milk in HMB since the composition of FAs remained unchanged. In addition, these authors suggested that this evaluation could be performed on vacuum-packed lyophilized milk in future works since their work was performed under the following two storage conditions: lyophilized $\mathrm{HM}$ at 4 and $40^{\circ} \mathrm{C}$, both packed separately in glass vials, indicating the presence of both air and light.

From the results presented in Tables S3-S5 (SI section) for the SFA, the palmitic acid (PA, 16:0) was the constituent with the highest concentration in $\mathrm{C}, \mathrm{T}$, and $\mathrm{M} \mathrm{HM}$, with the HM FA composition a result of the type and quantity of fat consumed in the maternal feeding at the stage of lactation, being responsible for variations in FAs. ${ }^{40}$ Kuipers et al ${ }^{41}$ found the sum of SFA ( $\Sigma$ SFA) values between 41.9 and $55.2 \%$ in $\mathrm{C}, \mathrm{T}$, and $\mathrm{M} \mathrm{HM}$, which are close to those obtained in this study (41.45-43.42\%).

In relation to the MUFA, the major constituent was oleic acid (OA, 18:1n-9) in C, T, and M HM. The $\Sigma$ MUFA values (36.26-36.89\%) were close to those found in other studies $^{41,42}$ for the three phases of HM.

The main FA that contributed to the sum of PUFA was linoleic acid (LA, 18:2n-6), with EPUFA values of $20.20-21.88 \%$ in the three phases of HM, with values also close to the study of Kuipers et al. ${ }^{41}$ for the three phases of HM.

Arachidonic acid (AA, 20:4n-6), docosahexanoic acid (DHA, 22:6n-3), and eicosapentaenoic acid (EPA, 20:5n-3) are important PUFA for child development. ${ }^{43}$ DHA has an influence on neuronal development and visual acuity and in conjunction with the EPA it helps the child's immune system. ${ }^{44}$ The presence of omega-3 FA (n-3) in HM is important for the development of the child's vision, retina, and brain. ${ }^{45}$ The amounts of AA, DHA, and EPA of the CL, $\mathrm{TL}$, and ML HM pool samples remained without significant differences during the analyzed period of storage, which is a great advantage when taking into account the importance of such FA.

The consideration of the $n-6 / n-3$ ratio is significant because the FA of these classes compete for the metabolic pathways of stretching and desaturation. According to Simopoulos, ${ }^{46}$ this ratio for proper functioning of the organism must be between 5 and 10. From Tables S3-S5 (SI section), the $\mathrm{n}-6 / \mathrm{n}-3$ ratio values found were between 8.72 and 10.85 , close to the value found by Mitoulas et al. ${ }^{47}$ in the first year of lactation (6.18-10.94).

\section{Triacylglycerol (TAG) composition}

The direct infusion by ESI-MS is a powerful technique that has been used in TAG analysis. It is a fast, sensitive, and simple method..$^{48}$ The lipid profile of the HM pool samples before (CO, T0 and M0) and after (CL0, TL0 and MLO) the lyophilization process, as well as the lyophilized HM pool samples during storage for 180 days, were obtained and the results are shown in Figures 1-3 for $\mathrm{C}, \mathrm{T}$ and M HM, respectively. For better visualization, the separated spectra of each sample are available in the Supplementary Information (Figures S10 to S33).

In addition, Tables S6-S8 (in the SI section) summarize the main TAGs identified from the ESI-MS lipid profiles. The TAGs were described in relative percentages; therefore, the most intense ion peak in each mass spectrum was designated as $100 \%$ and the others were assigned with the relative intensity in relation to the most intense peak. This study is the first to evaluate the TAG composition of lyophilized HM. However, the abbreviation of each TAG represents the three FAs regardless the specific order in TAG structure.

From the results (Tables S6-S8, SI section) obtained for HM before (samples $\mathrm{C} 0$, T0, and M0) and after the lyophilization process (samples CLO, TLO, and MLO), it was observed that the relative percentages of the major TAGs of the C, T, and M HM lipid samples were similar before and after the lyophilization process, indicating that the lipid profile did not change with the lyophilization process.

The TAGs with the highest intensities in the fat of the C, T, and M HM were in the range of $\mathrm{m} / \mathrm{z}$ 874-876, 

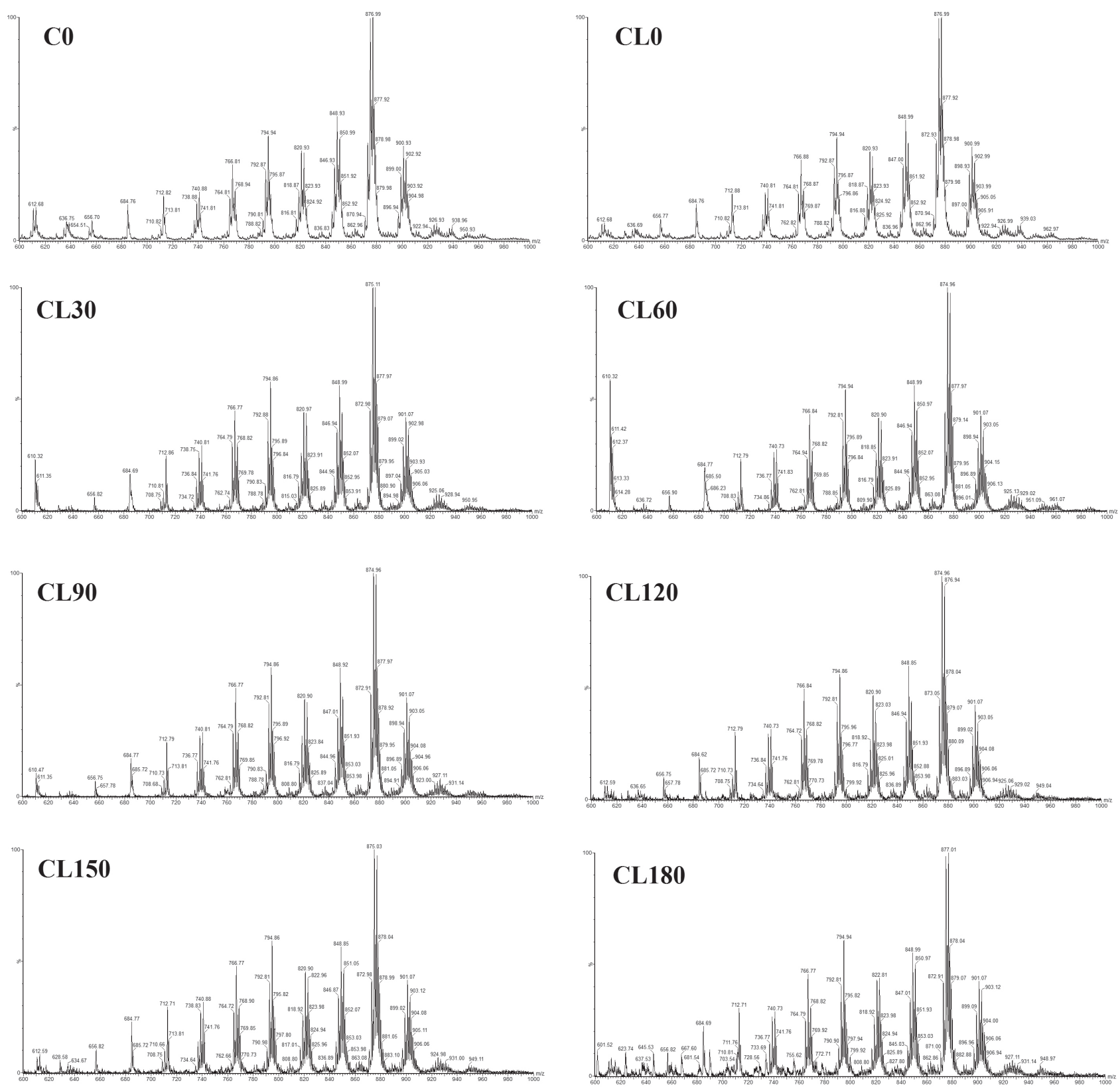

Figure 1. Lipid profile of the colostrum human milk before lyophilization ( $\mathrm{C} 0)$, and of the lyophilized colostrum human milk samples stored for 1 , 30, 60, 90, 120, 150 and 180 days (CL0 to CL180).

possibly the PLO, PDM, SLnP, OPoO, PEpP, SEpM, SLPo, MaMaLn, PoPoEi, PdLnHe, POO, ALM, SOPo, SLP, APoPo, PPoEi, LaOEr, with palmitic acid predominating among the combinations of TAGs. A is arachidic acid (20:0), D is docosahexaenoic acid (22:6n-3), Ei is eicosenoic acid (20:1n-9), Ep is eicosapentaenoic acid (20:5n-3), Er is erucic acid (22:1n-9), He is heneicosanoic acid (21:0), L is linoleic acid (18:2n-6), La is lauric acid (12:0), Ln is linolenic acid (18:3n-6), $\mathrm{M}$ is myristic acid (14:0), Ma is margaric acid (17:0), $\mathrm{O}$ is oleic acid (18:1n-9), $\mathrm{P}$ is palmitic acid (16:0), Pd is pentadecanoic acid (15:0), Po is palmitoleic acid (16:1), and $\mathrm{S}$ is stearic acid (18:0). These results are in accordance with the results obtained by GC-FID analysis presented in Tables S3 to S5 (SI section). The FAs 16:0, 18:1n-9 and 18:2n-6 showed higher concentrations in the HM samples analyzed by GC-FID, and the possible lipids found through the $\mathrm{m} / \mathrm{z}$ ratio by ESI(+)-MS were mainly composed of these three FAs.

The study by Kallio et al. ${ }^{49}$ also found that palmitic acid was the major constituent in the composition of the possible TAGs of the HM, which is affected by the eating habits of mothers. The high concentration of palmitic acid in TAGs is important since it remains in the stomach as 

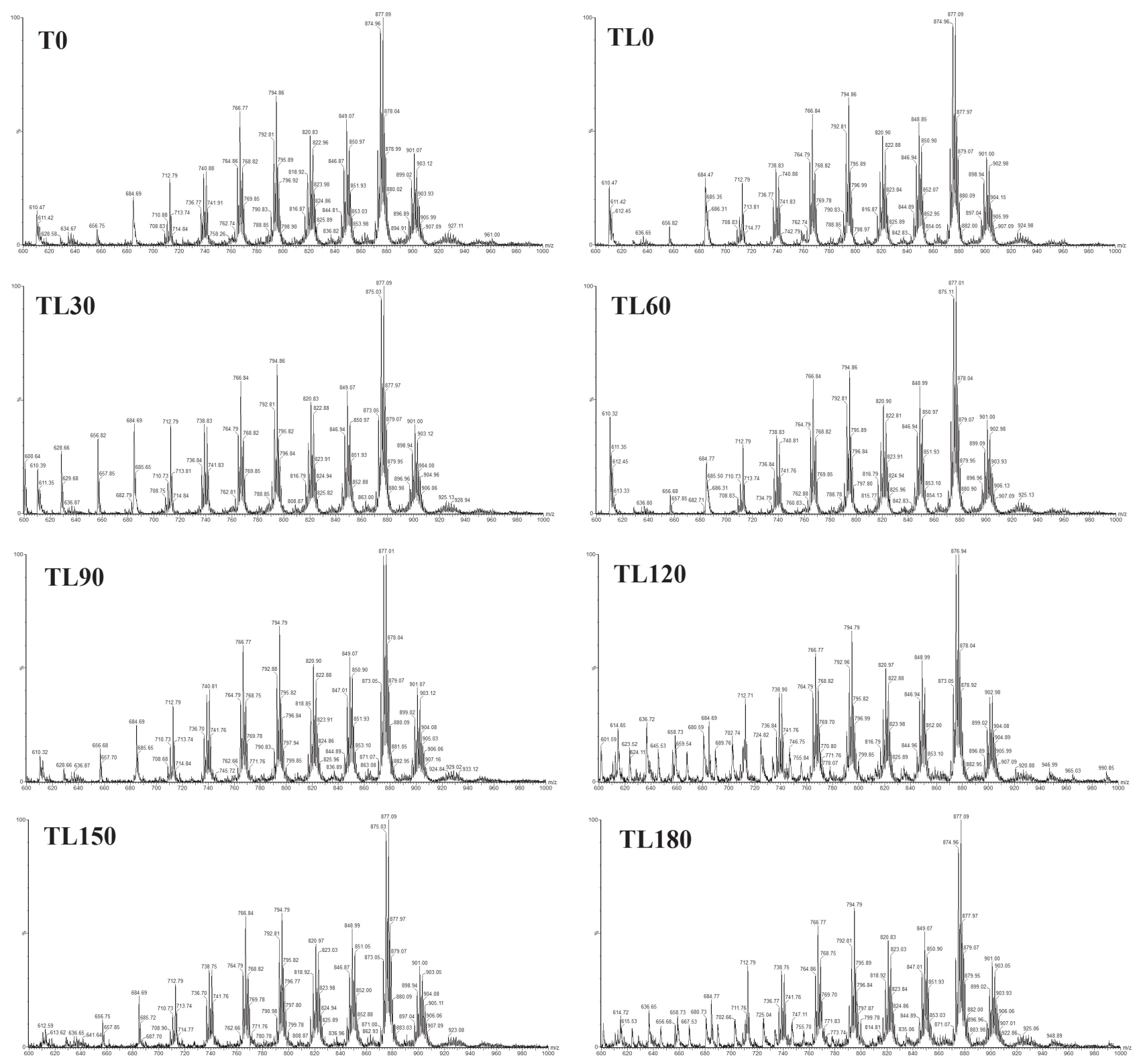

Figure 2. Lipid profile of the transitional human milk before lyophilization (T0), and of the lyophilized transitional human milk samples stored for 1, 30, 60, 90, 120, 150 and 180 days (TL0 to TL180).

2-monoacyl-sn-glycerols, which have protective effects for the child. ${ }^{50}$

It was also noted that the TAG relative percentages were not altered over the analyzed time, showing that the lyophilization process plus the vacuum packaging and freezer storage $\left(-18{ }^{\circ} \mathrm{C}\right.$ for 180 days) helped to maintain the characteristics of the HM TAG composition.

\section{Conclusions}

The FA composition, acidity ( ${ }^{\circ}$ Dornic), and lipid content of the C, T and M HM did not differ significantly before their lyophilization process. In addition, these characteristics did not differ significantly when the CL, TL and ML HM were vacuum packed and stored in a freezer at $-18{ }^{\circ} \mathrm{C}$ during 180 days of storage. From the relative percentage of the main TAGs identified by ESI-MS, it was observed that the lipid profile also did not change during this process. The lyophilization technique of colostrum, transitional and mature HM was adequate to be applied in $\mathrm{HMB}$, considering that it maintained the lipid composition, increasing the HM shelf life and making easier its transport and storage. In addition, it is easy to reconstitute the lyophilized HM to its initial product with the addition of water. 

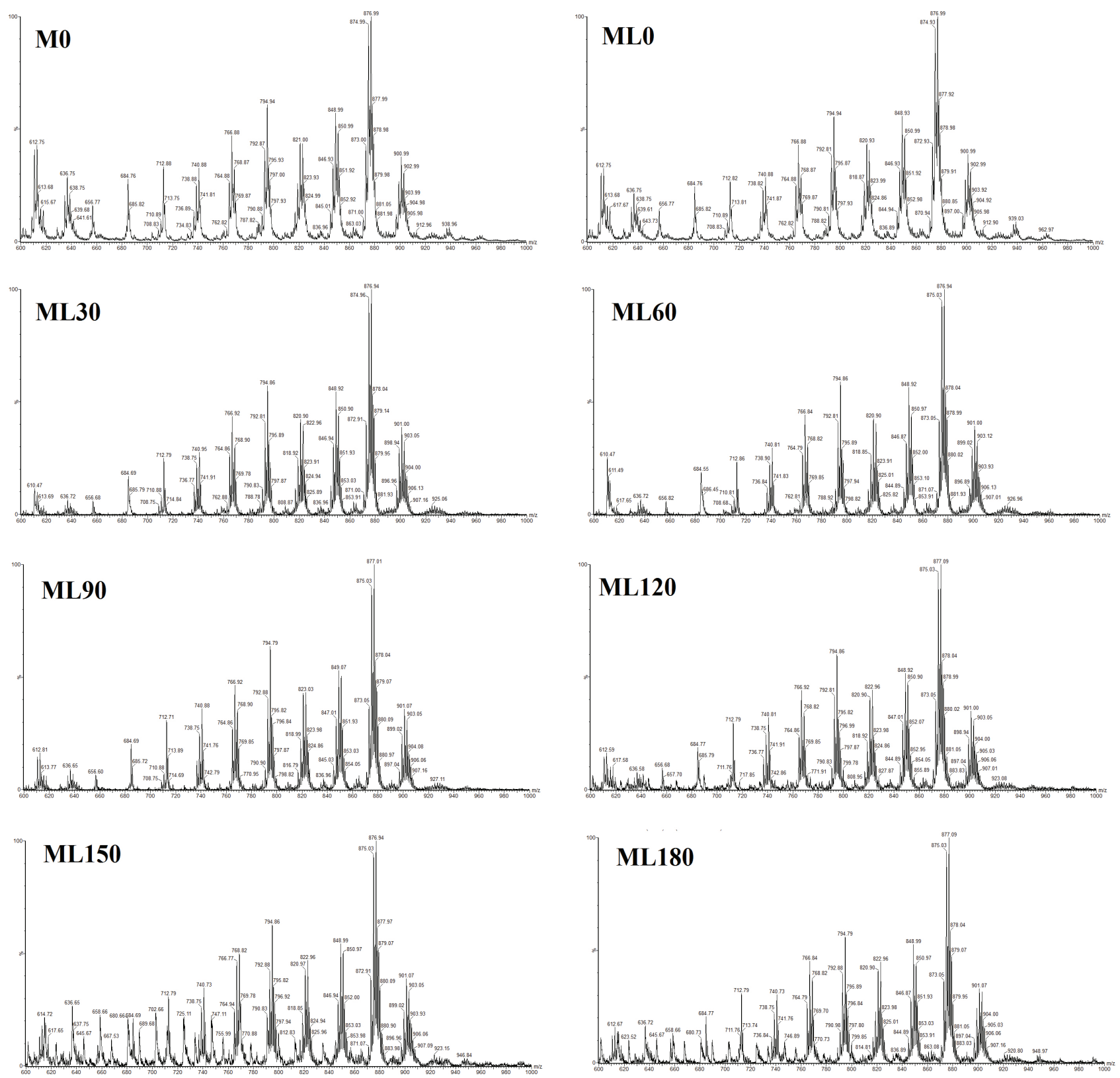

Figure 3. Lipid profile of the mature human milk before lyophilization (M0), and of the lyophilized mature human milk samples stored for 1, 30, 60, 90, 120,150 and 180 days (ML0 to ML180).

\section{Supplementary Information}

Supplementary data with the spectra of each sample separately are available free of charge at http://jbcs.sbq.org.br as a PDF file.

\section{Acknowledgments}

The authors are grateful to Conselho Nacional de Desenvolvimento Científico e Tecnológico (CNPq), Coordenação de Aperfeiçoamento de Pessoal de Nível Superior (CAPES), and Fundação Araucária de Apoio ao Desenvolvimento Científico e Tecnológico do Estado do Paraná (FAPPR) for financial assistance and the HMB for their partnership and donation of HM samples.

\section{References}

1. Johnston, M.; Landers, S.; Noble, L.; Szucs, K.; Viehmann, L.; Pediatrics 2012, 129, 827.

2. Bernt, K. M.; Walker, W.; Acta Paediatr., Suppl. 1999, 88, 27.

3. Boccolini, C. S.; Carvalho, M. L.; Oliveira, M. I. C.; Boccolini, P. M. M.; J. Pediatr. 2011, 87, 399. 
4. Dórea, J. G.; Fenton, S. E.; Lakind, J. S.; Berlin, C. M.; Bosnian J. Basic Med. Sci. 2012, 12, 137.

5. Matheson, M. C.; Allen, K. J.; Tang, M. L. K.; Clin. Exp. Allergy 2012, $42,827$.

6. Leaf, A.; Winterson, R.; Paediatr. Child Health 2009, 19, 395.

7. Koletzko, B.; Ann. Nutr. Metab. 2017, 69, 28.

8. Almansa, I.; Miranda, M.; Jareño, E.; Silvestre, D.; Int. Dairy J. 2013, 33, 83 .

9. Ballard, O.; Morrow, A. L.; Pediatr. Clin. North Am. 2013, 60, 49.

10. Jensen, R. G.; Hagerty, M. M.; McMahon, K. E.; Am. J. Clin. Nutr. 1978, 31, 990.

11. Vieira, A. A.; Soares, F. V. M.; Pimenta, H. P.; Abranches, A. D.; Moreira, M. E. L.; Early Hum. Dev. 2011, 87, 577.

12. Samur, G.; Topcu, A.; Turan, S.; Lipids 2009, 44, 405.

13. Demmelmair, H.; Baumheuer, M.; Koletzko, B.; Dokoupil, K.; Kratl, G.; J. Lipid Res. 1998, 39, 1389.

14. Mohammad, M. A.; Haymond, M. W.; Am. J. Physiol.: Endocrinol. Metab. 2013, 305, 700.

15. Akinbi, H.; Meinzen-Derr, J.; Auer, C.; Ma, Y.; Pullum, D.; Kusano, R.; Reszka, K. J.; Zimmerly, K.; J. Pediatr. Gastroenterol. Nutr. 2010, 51, 347.

16. Ford, J.; Law, B.; Marshall, V.; Reiter, B.; J. Pediatr. 1977, 90 , 29.

17. Permanyer, M.; Castellote, C.; Ramírez-Santana, C.; Audí, C.; Pérez-Cano, F. J.; Castell, M.; López-Sabater, M. C.; Franch, À.; J. Dairy Sci. 2010, 93, 877.

18. Friend, B. A.; Shahani, K. M.; Long, C. A.; Vaughn, L. A.; Pediatr. Res. 1983, 17, 61.

19. Keenan, T. W.; Mather, I. H.; Adv. Dairy Chem. 2009, $2,137$.

20. Sousa, P. P. R.; Silva, J. A.; Rev. Inst. Adolfo Lutz 2009, 69, 7.

21. Borgo, L. A.; Araújo, W. M. C.; Conceição, M. H.; Resck, I. S.; Mendonça, M. A.; Nutr. Hosp. 2014, 31, 1386.

22. Shofian, N. M.; Hamid, A. A.; Osman, A.; Saari, N.; Anwar, F.; Dek, M. S. P.; Hairuddin, M. R.; Int. J. Mol. Sci. 2011, 12, 4678.

23. Silvestre, D.; Miranda, M.; Muriach, M.; Almansa, I.; Jareño, E.; Romero, F. J.; J. Hum. Lact. 2010, 26, 35.

24. Salcedo, J.; Gormaz, M.; López-Mendoza, M. C.; Nogarotto, E.; Silvestre, D.; J. Pediatr. Gastroenterol. Nutr. 2015, 60, 527.

25. Du, J.; Gay, M. C. L.; Lai, C. T.; Trengove, R. D.; Hartmann, P. E.; Geddes, D. T.; Food Chem. 2017, 217, 505.

26. Martysiak-Żurowska, D.; Puta, M.; Rodzik, A.; MalinowskaPańczyk, E.; Zywn-Nauk. Technol. Ja. 2017, 24, 121.

27. Almeida, J. A. G.; Guimarães, V.; Novak, F. R.; Normas Técnicas REDEBLH-BR para Bancos de Leite Humano; Centro de Referência Nacional para Bancos de Leite Humano: Rio de Janeiro, 2005.

28. http://www.redeblh.fiocruz.br/media/blhanv2008.pdf, accessed in August 2018.

29. Folch, J.; Lees, M.; Stanley, G. H. S.; J. Biol. Chem. 1957, 226, 497.
30. Hartman, L.; Lago, R. C.; Lab. Pract. 1973, 22, 475.

31. Maia, E. L.; Rodriguez-Amaya, D. B.; Rev. Inst. Adolfo Lutz 1993, 53, 27.

32. Simionato, J. I.; Garcia, J. C.; dos Santos, G. T.; Oliveira, C. C.; Visentainer, J. V.; de Souza, N. E.; J. Braz. Chem. Soc. 2010 , 21,520 .

33. Galuch, M. B.; Carbonera, F.; Magon, T. F. S.; da Silveira, R.; dos Santos, P. D. S.; Pizzo, J. S.; Santos, O. O.; Visentainer, J. V.; J. Braz. Chem. Soc. 2018, 29, 631.

34. Silveira, R.; Vágula, J. M.; Figueiredo, I. L.; Claus, T.; Galuch, M. B.; Santos Jr., O. O.; Visentainer, J. V.; Food Res. Int. 2017, $102,43$.

35. Hammer, Ø.; Harper, D. A. T.; Ryan, P. D.; Palaeontol. Electron. 2001, 4, art. 4.

36. Vázquez-Román, S.; Garcia-Lara, N. R.; Escuder-Vieco, D.; Chaves-Sánchez, F.; Cruz-Bertolo, J.; Pallas-Alonso, C. R.; Breastfeed. Med. 2013, 8, 99.

37. Pereira, C. I. V.; Dametto, J. F. S.; Oliveira, J. C. C.; J. Pediatr. 2016, 92, 499.

38. Andersson, Y.; Sävman, K.; Bläckberg, L.; Hernell, O.; Acta Paediatr. 2007, 96, 1445.

39. Lozano, B.; Castellote, A. I.; Montes, R.; López-Sabater, M. C.; Int. J. Food Sci. Nutr. 2014, 65, 703.

40. Wu, T. C.; Lau, B. H.; Chen, P. H.; Wu, L. T.; Tang, R. B.; J. Chin. Med. Assoc. 2010, 73, 581.

41. Kuipers, R. S.; Luxwolda, M. F.; Dijck-Brouwer, D. A. J.; Muskiet, F. A. J.; Prostaglandins, Leukotrienes Essent. Fatty Acids 2012, 86, 201.

42. Lubetzky, R.; Argov-Argaman, N.; Mimouni, F. B.; Domany, K. A.; Shiff, Y.; Berkovitz, Z.; Reifen, R.; Mandel, D.; J. Matern.Fetal Neonat. Med. 2016, 29, 3041.

43. Huffman, S. L.; Harika, R. K.; Eilander, A.; Osendarp, S. J. M.; Matern. Child Nutr. 2011, 7, 44.

44. Nishimura, R. Y.; Castro, G. S. F.; Jordão, A. A.; Sartorelli, D. S.; J. Pediatr. 2013, 89, 263.

45. Eltweri, A. M.; Thomas, A. L.; Metcalfe, M.; Calder, P. C.; Dennison, A. R.; Bowrey, D. J.; Clin. Nutr. 2017, 36, 65.

46. Simopoulos, A. P.; World Rev. Nutr. Diet. 2003, 92, 1.

47. Mitoulas, L. R.; Gurrin, L. C.; Doherty, D. A.; Sherriff, J. L.; Hartmann, P. E.; Br. J. Nutr. 2003, 90, 979.

48. Cabral, E. C.; da Cruz, G. F.; Simas, R. C.; Sanvido, G. B.; Gonçalves, L. V.; Leal, R. V. P.; da Silva, R. C. F.; da Silva, J. C. T.; Barata, L. E. S.; da Cunha, V. S.; de França, L. F.; Daroda, R. J.; de Sá, G. F.; Eberlin, M. N.; Anal. Methods 2013, 5, 1385.

49. Kallio, H.; Nylund, M.; Boström, P.; Yang, B.; Food Chem. 2017, 233, 351.

50. Kelsey, J. A.; Bayles, K. W.; Shafii, B.; McGuire, M. A.; Lipids 2006, 41,951 .

Submitted: September 20, 2018

Published online: March 25, 2019 